\title{
A CPT-based Effective Stress Analysis Procedure for Liquefaction Assessment
}

$5^{\text {th }}$ QuakeCoRE Annual Meeting

7-10 December 2020

Nikolaos NTRITSOS ${ }^{1}$, Misko CUBRINOVSKI ${ }^{1}$

Rutherford Hotel, Whakatū | Nelson

${ }^{1}$ University of Canterbury, Christchurch, New Zealand

\section{Overview}

Key steps of a procedure for 1D effective stress analysis of free-field soil columns are presented [1]. The proposed procedure can be fully automated in a programming environment, and it is directly equivalent (in the definition of liquefaction resistance and required input data) to the CPT-based simplified procedures for liquefaction assessment. These features allow advanced effective-stress analysis to be routinely applied in practice, in parallel with simplified procedures.

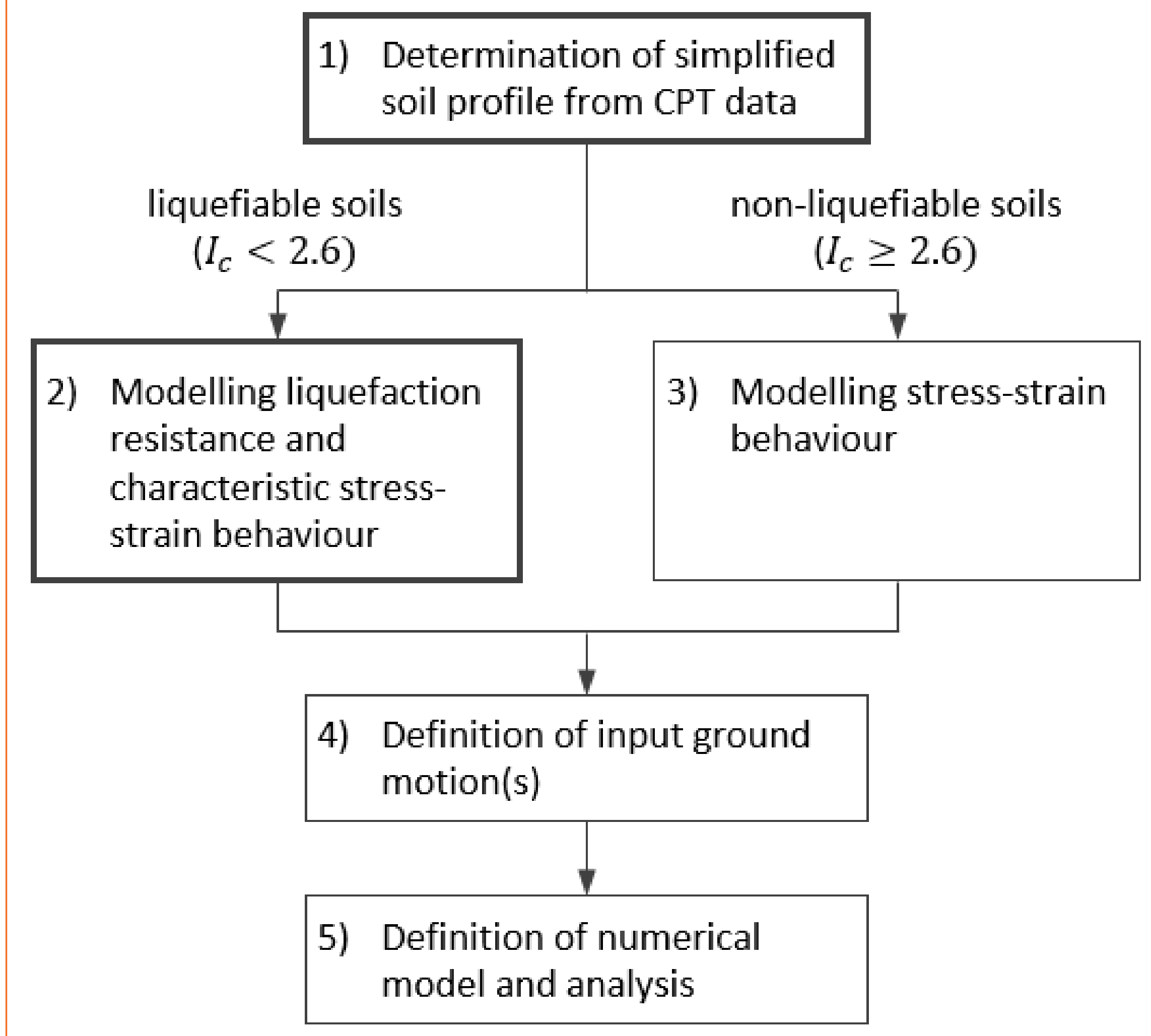

Figure 1. Key steps in the proposed CPT-based effective stress analysis procedure.

\section{Determination of simplified soil proffle}

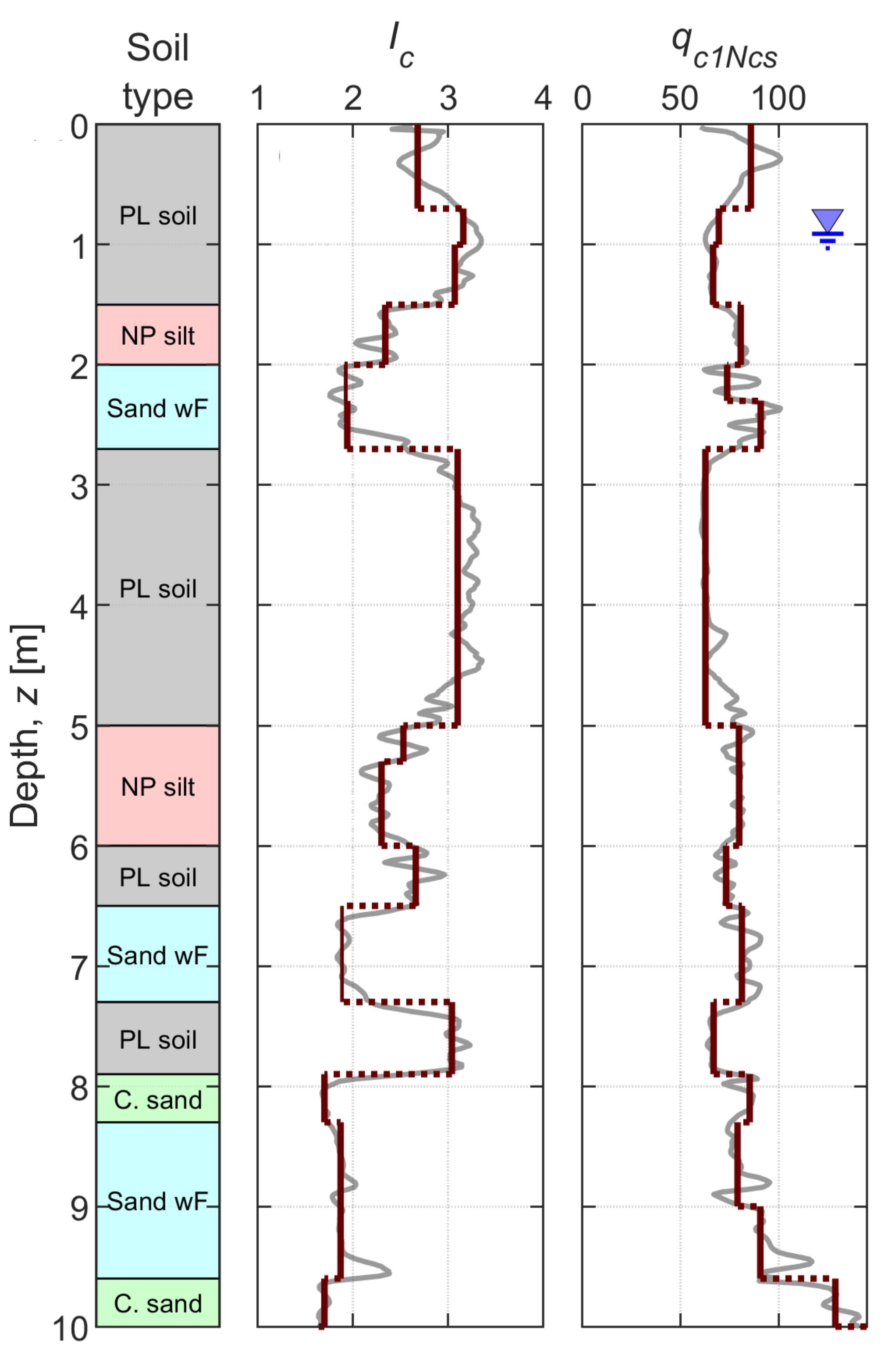

Figure 2. Determination of a simplified (discretized) soil profile from the nearly continuous CPT data.
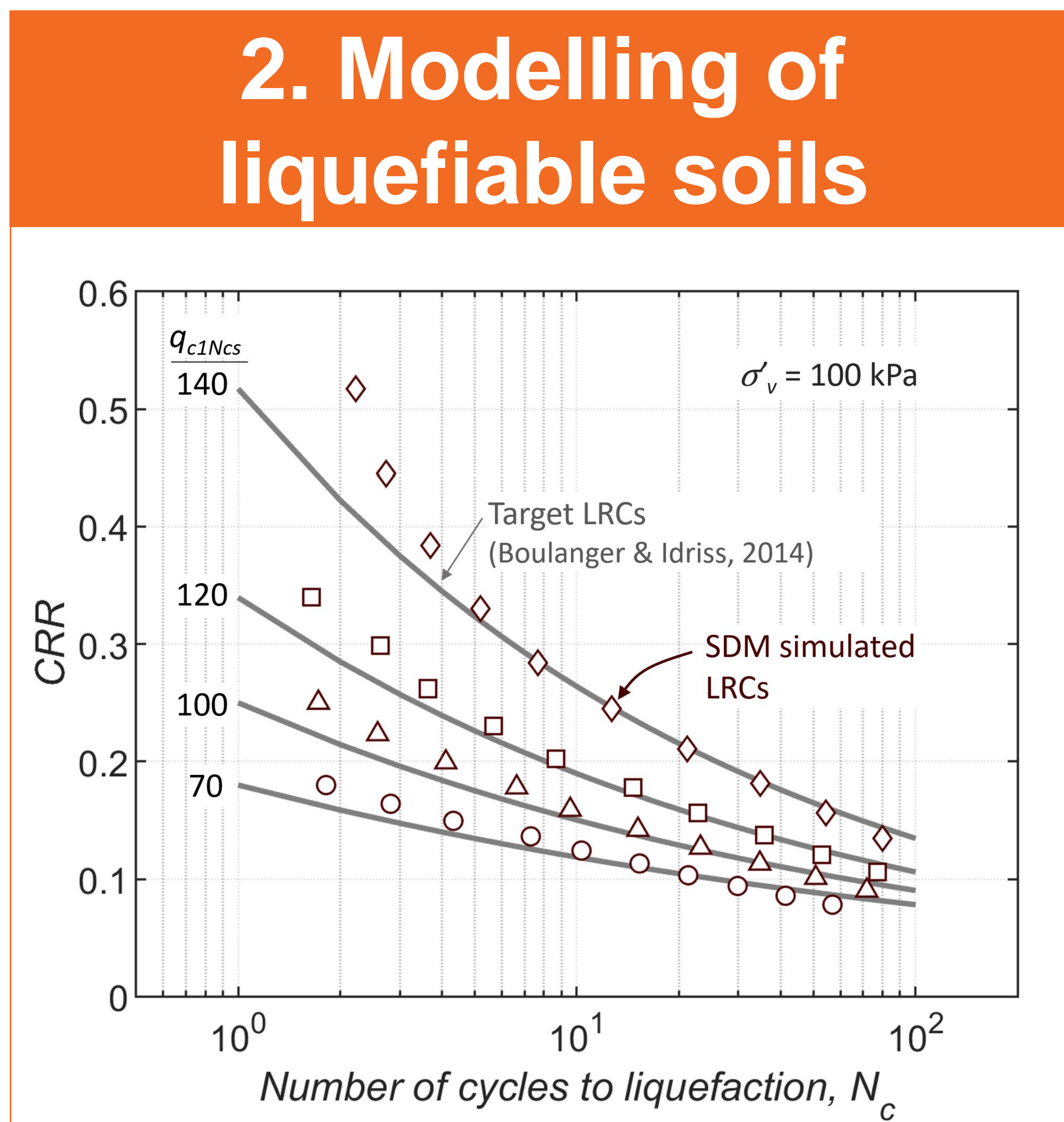

Figure 3. Modelling of liquefiable soils focuses on the simulation of their (cyclic) liquefaction resistance. Target liquefaction resistance curves (solid lines), obtained based on simplified liquefaction triggering procedures, are used to calibrate a constitutive model (SDM) capable of reproducing callo ( es for model parameters.

\section{Modelling of non-liquefiable soils}

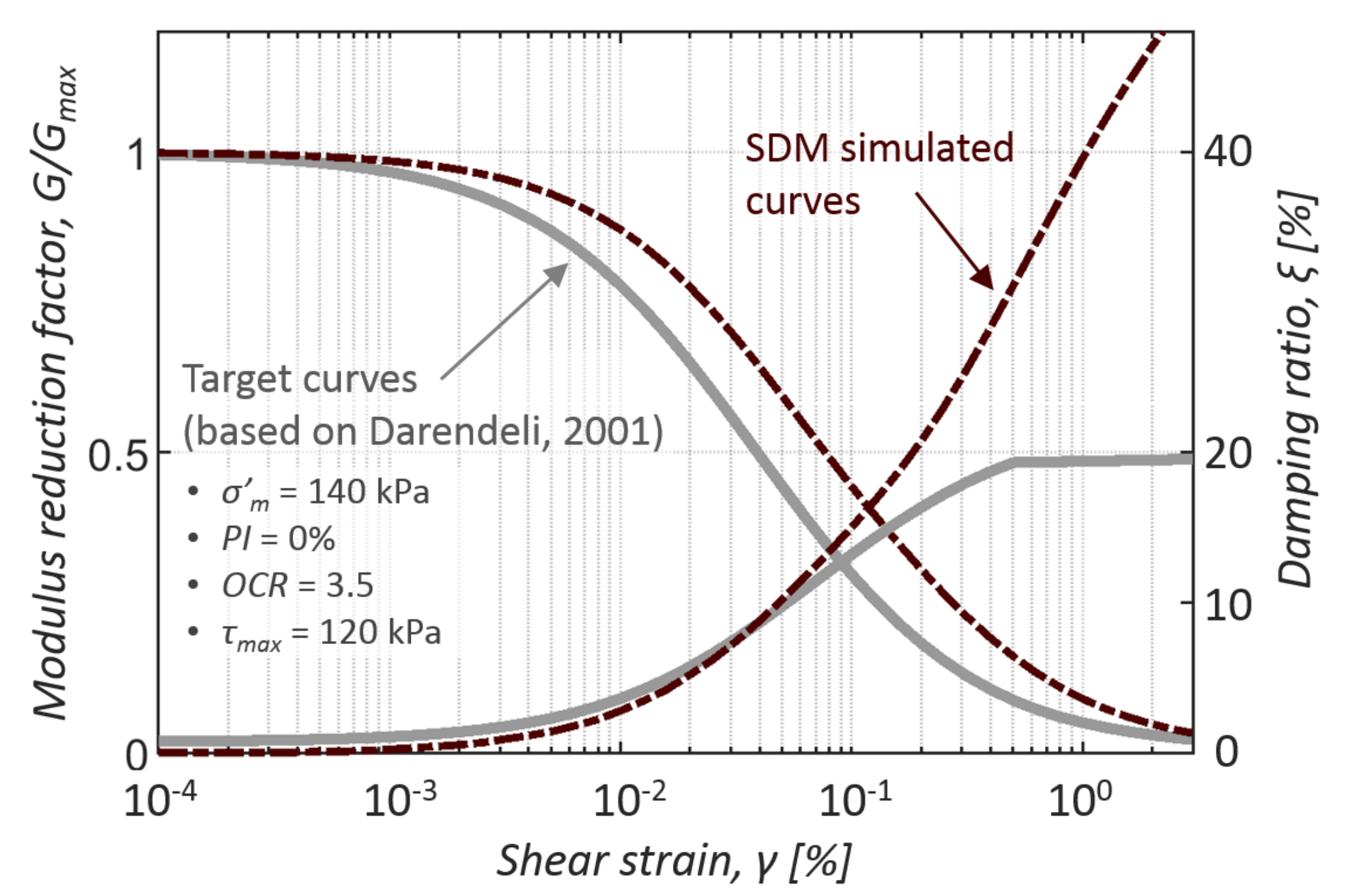

Figure 4. Modelling of non-liquefiable soils targets their cyclic stress-strain response, defined in terms of generic modulus reduction and damping ratio curves. The calibration of the constitutive model aims at providing a reasonably accurate and concurrent modelling of the target curves over the expected range of shear strains.

\section{Definition of input motions}

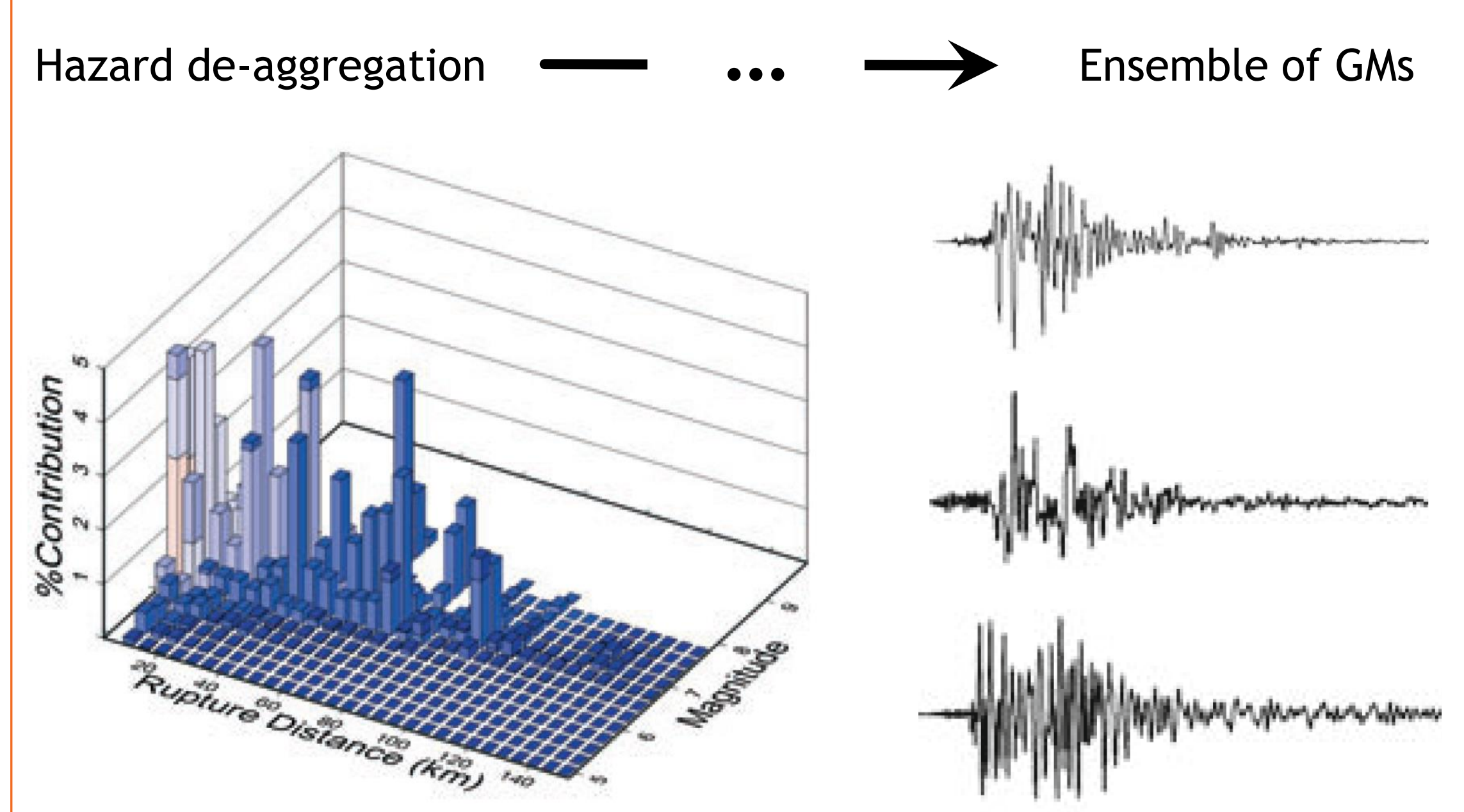

Figure 5. An ensemble of input ground motions is selected for a specified level of hazard based on established ground motion selection procedures (e.g. [2])

\section{Numerical model \& analysis parameters}

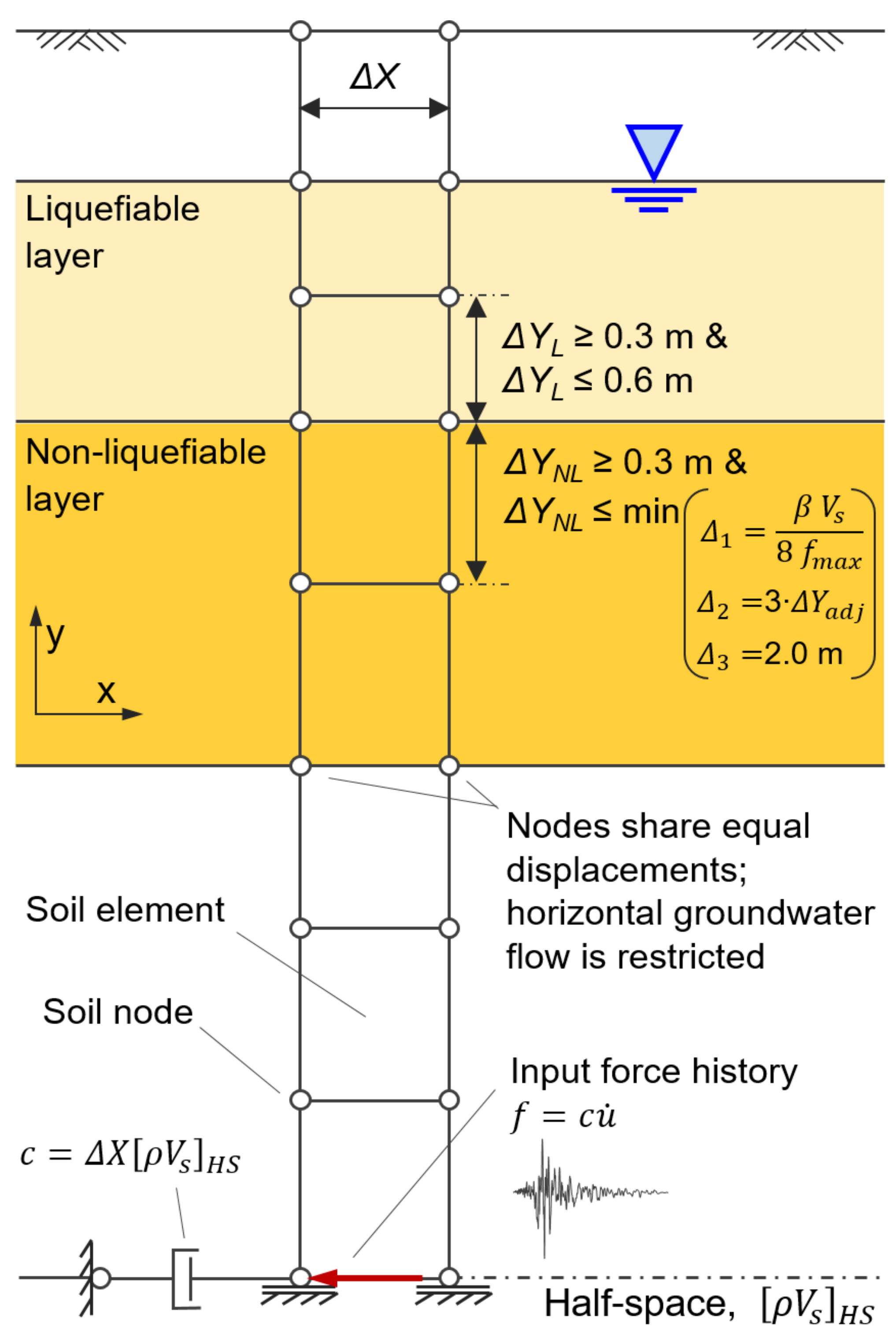

Figure 6. The final step entails the definition of element size, boundary conditions, initial stress state of the soil, and analysis parameters (e.g. computation time increment, integration scheme, numerical damping)

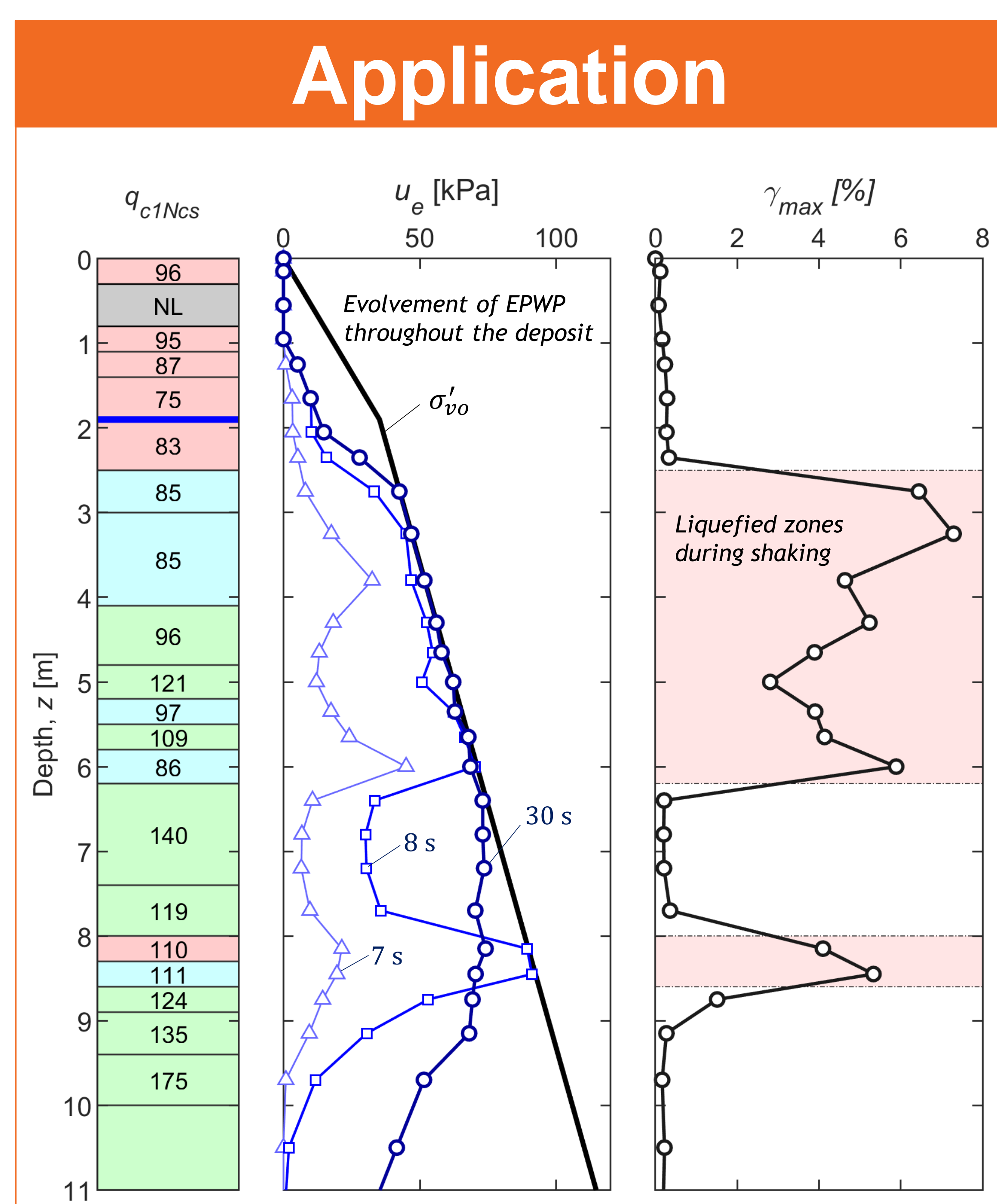

Figure 7. The proposed effective stress analysis procedure can capture key aspects of the response of liquefiable soils and deposits, including pore water pressure development, triggering of soil liquefaction, and resulting deformations during the dynamic shaking and post-shaking dissipation of ( mechanisms involving cross interaction amongst different soil layers in the dynamic response and through pore water pressure redistribution and water flow are rigorously simulated in the analysis.

\section{Contact}

Nikolaos Ntritsos

University of Canterbury, Christchurch, New Zealand Email: nikolaos.ntritsos@pg.canterbury.ac.nz

\section{References}

